\title{
Fine-grained precursors dominate the micrometeorite flux
}

\author{
Susan TAYLOR ${ }^{1 *}$, Graciela MATRAJT ${ }^{2}$, and Yunbin GUAN ${ }^{3}$ \\ ${ }^{1}$ Cold Regions Research and Engineering Laboratory, 72 Lyme Road, Hanover, New Hampshire 03755-1290, USA \\ ${ }^{2}$ University of Washington, Seattle, Washington 98105, USA \\ ${ }^{3}$ Geological \& Planetary Sciences MC 170-25, Caltech, Pasadena, California 91125, USA \\ "Corresponding author. E-mail: susan.taylor@usace.army.mil
}

(Received 15 May 2011; revision accepted 22 September 2011)

\begin{abstract}
We optically classified 5682 micrometeorites (MMs) from the 2000 South Pole collection into textural classes, imaged 2458 of these MMs with a scanning electron microscope, and made 200 elemental and eight isotopic measurements on those with unusual textures or relict phases. As textures provide information on both degree of heating and composition of MMs, we developed textural sequences that illustrate how fine-grained, coarse-grained, and single mineral MMs change with increased heating. We used this information to determine the percentage of matrix dominated to mineral dominated precursor materials (precursors) that produced the MMs. We find that at least $75 \%$ of the MMs in the collection derived from fine-grained precursors with compositions similar to CI and CM meteorites and consistent with dynamical models that indicate $85 \%$ of the mass influx of small particles to Earth comes from Jupiter family comets. A lower limit for ordinary chondrites is estimated at $2-8 \%$ based on MMs that contain Na-bearing plagioclase relicts. Less than $1 \%$ of the MMs have achondritic compositions, CAI components, or recognizable chondrules. Single mineral MMs often have magnetite zones around their peripheries. We measured their isotopic compositions to determine if the magnetite zones demarcate the volume affected by atmospheric exchange during entry heating. Because we see little gradient in isotopic composition in the olivines, we conclude that the magnetites are a visual marker that allows us to select and analyze areas not affected by atmospheric exchange. Similar magnetite zones are seen in some olivine and pyroxene relict grains contained within MMs.
\end{abstract}

\section{INTRODUCTION}

Micrometeoroids are the largest source of extraterrestrial materials arriving to Earth today (30,000 ton $\mathrm{yr}^{-1}$, Love and Brownlee 1993). Not all micrometeoroids, however, reach the Earth's surface as particles. Micrometeorites (MMs) are the surviving fraction collected at the Earth's surface and measuring $50 \mu \mathrm{m}$ to $2 \mathrm{~mm}$ in diameter. Their terrestrial accretion rate of $2700 \pm 1400$ ton $\mathrm{yr}^{-1}$ (Taylor et al. 1998), suggests that over $90 \%$ of the micrometeoroid influx evaporates passing through the atmosphere, a value consistent with modeling results (Love and Brownlee 1991; Alexander 2001). Despite the high fraction that evaporates, the MM accretion rate is 100 times higher than that estimated for meteorites $\left(\sim 50\right.$ ton $\mathrm{yr}^{-1}$, Zolensky et al. 2006).
Micrometeoroids show a variety of heating effects ranging from unmelted particles with low temperature mineral transformations (Greshake et al. 1998) to isotopically fractionated spherules that have suffered significant evaporation (Alexander et al. 2002; Taylor et al. 2005). Cosmic spherules refer to those MMs, about $80 \%$, that have been completely or partially melted entering the atmosphere and that consequently have round shapes. Unmelted MMs are particles that were not significantly melted or contain $>50 \%$ relic phases and whose shapes are often irregular.

The origin of individual MMs is difficult to determine due to their small size and the compositional and textural changes brought on by atmospheric entry heating and subsequent terrestrial weathering. If we could determine their origin, analyses of these samples 
could be used as "ground truth" for astronomical observations and could help probe larger scale solar system processes. To match MMs to parent sources, researchers analyze major, minor, and trace element and oxygen isotope compositions of MMs to compare with samples of meteorites and comets (e.g., comet 81P/Wild 2, Brownlee et al. 2006). Meteor spectra also provide data on major element abundances (Trigo-Rodriguez et al. 2003) and dynamical simulations provide information on where small particles that form the zodiacal cloud, and become MMs, originate (e.g., Nesvorný et al. 2010).

Elemental, isotopic, and textural comparisons have been used to link individual MMs to meteorite groups. Unmelted MMs show the least effects of heating. Consequently, their compositions are compared directly to those of meteorites. Compared to bulk meteorite compositions fine-grained unmelted $\mathrm{MMs}$ are most similar to CI, CR, and CM meteorites (Kurat et al. 1994; Beckerling and Bischoff 1995; Greshake et al. 1998) and their relict grains are also consistent with those meteorite types (Beckerling and Bischoff 1995; Walter et al. 1995; Engrand et al. 1999). The compositions and assemblages of minerals in unmelted coarse-grained MMs correspond to a wider distribution of meteorite types including a contribution from ordinary chondrites (OC) (Genge 2008; Imae et al. 2010).

For melted cosmic spherules the ratios of nonvolatile elements such as $\mathrm{Mg}, \mathrm{Si}, \mathrm{Al}$, and $\mathrm{Ca}$ are compared to element ratios from bulk meteorites and most show similarities to CM meteorites (Brownlee et al. 1997; Taylor et al. 2000) but not to ordinary chondrites (Brownlee et al. 1997). Plots of $\mathrm{Si} / \mathrm{Al}$ versus $\mathrm{Mg} / \mathrm{Al}$, for example, can distinguish between spherules derived from fine-grained chondritic precursors from those primarily composed of coarse-grained precursors (Taylor et al. 2005).

Plots of $\mathrm{Fe} / \mathrm{Mg}$ versus $\mathrm{Mn} / \mathrm{Mg}$ can distinguish between chondritic and achondrite sources (Goodrich and Delaney 2000) and show that most MMs plot within the chondritic region and only a few, half a percent of the MM influx, are achondritic (Taylor et al. 2007). These plot in the same region as the basaltic howardite, eucrite, and diogenite (HED) meteorites and Martian meteorites and were most similar to eucrite meteorites from Vesta (Taylor et al. 2007). Cordier et al. (2011) used the oxidation state of rare earth and siderophile elements to further distinguish between a HED or Martian meteorite origin.

Oxygen isotopes provide another, independent method of linking MMs to specific meteorites. Oxygen isotope data on relict grains in MMs (Engrand et al. 1999; Taylor et al. 2005) showed that these are similar to minerals found in CI chondrites (Leshin et al. 1997). However, analyses of unmelted fine-grained MMs (Matrajt et al. 2006) and of cosmic spherules (Taylor et al. 2005; Yada et al. 2005) yield $\delta^{18} \mathrm{O}$ values that encompassed all known meteorite groups and could not be linked to specific meteorites. High-precision oxygen isotope analyses made on large, $>400 \mu \mathrm{m}$, cosmic spherules show that the $\delta^{18} \mathrm{O}$ values are more positive than, and do not overlie regions occupied by, the different meteorite groups in three oxygen isotope plots. These $\delta^{18} \mathrm{O}$ data are interpreted as meteorite material that was both isotopically fractionated and exchanged oxygen during entry heating.

We examined 5682 MMs using a light microscope, which allows us to distinguish between the textural classes and classified them. We then imaged 2458 of these MMs with a scanning electron microscope. We used the textures of the MMs along with elemental $(\sim 200)$ and isotopic (8) measurements on individual MMs to determine precursors of specific types of MMs and their percent contribution to the 2000 South Pole water well (SPWW) collection. We present a heating sequence for fine-grained, coarse-grained, and single mineral (SM) precursors and illustrate how their textures change with increasing heating and based on this sequence, we estimate the percentage of matrix-dominated to mineraldominated precursors. Using fine-grained to coarsegrained textures as well as some compositional indicators, we estimate the $\mathrm{CI} / \mathrm{CM}$-chondrite to ordinary chondrite (OC) fraction in the collection.

\section{METHODS}

\section{Sample Collection}

These samples were collected in 2000 from the SPWW, a $4000 \mathrm{~m}^{3}$ reservoir that melted pre-industrial ice. Melting in the well occurred slowly and continuously. Warm water was introduced $10 \mathrm{~m}$ above the well bottom, the flow was laminar, and bulk water temperatures were less than $2{ }^{\circ} \mathrm{C}$. The well melted downward at a rate of about $2 \mathrm{~cm} \mathrm{day}^{-1}$, allowing no freeze-back. The well bottom was smooth, although sculptured, and fracture free. When we collected these samples, the well was $134 \mathrm{~m}$ deep and was actively melting ice deposited in 800 AD (Kuivinen et al. 1982). We vacuumed the well bottom using a similar collector and technique as in 1995 (Taylor et al. 1997), which yielded the first fluxcalibrated MM collection (Taylor et al. 1998). These collection techniques are unbiased with respect to MM composition from 50 to $2000 \mu \mathrm{m}$ (Taylor et al. 1997, 1998).

\section{Sample Preparation and Analysis}

About $15 \mathrm{~g}$ of material were retrieved from the well bottom. Of this, $10 \mathrm{~g}$ was sieved and, using a binocular 
microscope, we sorted $100 \%$ of the $>150 \mu \mathrm{m}$ fractions, $29 \%$ of the $106-150 \mu \mathrm{m}$ fraction and $8.9 \%$ of the $53-106 \mu \mathrm{m}$ fraction. We transferred all potential extraterrestrial grains manually using a fine paintbrush to Plexiglas mounts. These were filled with epoxy and sectioned by polishing. Of the potted grains, 3272 were MMs. We also sieved $1 \mathrm{~g}$ of the remaining $5 \mathrm{~g}$, optically sorted all of the material larger than $50 \mu \mathrm{m}(0.4 \mathrm{~g})$ and potted and sectioned the samples. We found $2410 \mathrm{MMs}$ in these mounts. Altogether we sectioned and optically classified 5682 MMs. Taylor et al. (2007) show the size distributions for these MMs.

To obtain more detailed information about textures and compositions, we imaged 2458 of these MMs using the FEI XL-30 field scanning electron microscope at Dartmouth College. We spot checked the composition of many of the MMs by placing the beam on them for a few seconds and we stored $100 \mathrm{~s}$ analyses for $200 \mathrm{MMs}$, often those with unusual relict grains and textures. The FEI XL-30 has both secondary and backscatter electron detectors and an X-ray microanalysis light element $\mathrm{Si}$ (Li) detector for analyses of all elements heavier than carbon. Extraterrestrial indicators include a chondritic composition (as established by the relative concentrations of $\mathrm{Mg}, \mathrm{Al}, \mathrm{Si}, \mathrm{Ca}$, and $\mathrm{Fe}$ ), presence of magnetite rims around the particles, and a fine-grained matrix rich in $\mathrm{S}$ and $\mathrm{Ni}$.

We measured oxygen isotopes on two relict spinel grains, to determine if they were similar to spinels found in calcium-aluminum inclusions (CAIs), and on four SMs of olivine to determine if we could see a gradient in the oxygen isotope composition indicative of oxygen exchange with the Earth's atmosphere. These measurements were made using the Cameca 7f GEO at California Institute of Technology. A Cs ${ }^{+}$beam of approximately 2-3 nA in intensity and approximately $25 \mu \mathrm{m}$ in diameter was used to sputter the gold-coated sample surface and to produce secondary ions. Two different analytical procedures were applied. First, we used a low mass resolution of about 1500 to measure only ${ }^{18} \mathrm{O}$ and ${ }^{16} \mathrm{O}$ ions using two Faraday cups. Typical errors of repeated measurements of the San Carlos standard were about $1 \%(1 \sigma)$. Threeisotope measurements were then carried out with a mass resolution of about 6000 to separate the ${ }^{16} \mathrm{OH}^{-}$peak from the ${ }^{17} \mathrm{O}^{-}$peak. Only ${ }^{16} \mathrm{O}^{-}$ions were measured with the Faraday cup, whereas ${ }^{17} \mathrm{O}^{-}$and ${ }^{18} \mathrm{O}^{-}$were measured with an electron multiplier. Typical errors in repeated measurements of standards under these conditions were about $1.5 \%(1 \sigma)$.

\section{Micrometeorites Classification}

We classified MMs based on their degree of heating and on their compositions: chondritic and nonchondritic
(Taylor and Lever 2001; Genge et al. 2008). Low to high heating produces MMs with the following textures: fine- and coarse-grained unmelted (Figs. 1A and 1B); scoriaceous (Fig. 1C); relict-grain bearing (RGB) (Fig. 1D); porphyritic (Fig. 1E); barred olivine (Fig. 1F); cryptocrystalline (Fig. 1G); glass (Fig. 1H); and calciumaluminum-titanium (CAT) spherules (Fig. 1I). The latter, having experienced significant evaporation entering the Earth's atmosphere, are no longer chondritic and are highly depleted in Fe (Alexander et al. 2002). Glassy (G-type) (Fig. 1J) and iron (I-type) (Fig. 1K) MMs and those derived from SM (Fig. 1J) are also not chondritic in composition.

\section{RESULTS}

\section{Terrestrial Weathering}

Residence in the acidic water of the SPWW oxidizes metal, preferentially dissolves Ni-rich metal, and dissolves glasses. Nevertheless, most of the SPWW MMs look unweathered, as illustrated by a typical glass spherule (Fig. 2A). A few percent of the glass spherules have lost their circular outlines (Fig. 2B) and the peripheries of others are flaking off (Fig. 2C). Relative to the composition of the interior of the spherule, the glass flakes are $\mathrm{Mg}$-rich and $\mathrm{Fe}$-poor suggesting that $\mathrm{Fe}$ has been preferentially leached from the rim. Glass with high Fe content (the Gtype spherules) and glass with low Fe content (between the olivine crystals in the CAT spherules) (see Figs. 1B and 1C) is also preferentially dissolved in the SPWW. Their small numbers and easy identification allowed us to focus mainly on unweathered MMs. Nevertheless, to avoid any effects of terrestrial alteration we analyzed the centers of sectioned MMs.

\section{Micrometeorite Classes in the Collection}

Figure 3 is a plot of number versus type of MMs for three size fractions $0-100,100-250$, and $>250 \mu \mathrm{m}$. For the two largest size fractions glass spherules are most common followed by barred olivine, fine-grained unmelted, and porphyritic MMs. For MMs $0-100 \mu \mathrm{m}$ in diameter, barred olivine, porphyritic, and glass MMs are the most common types. Of the $5682 \mathrm{MM}$ classified, 9\% were finegrained unmelted, 4\% coarse-grained unmelted, $6 \%$ scoriaceous, 3\% RGB, 15\% porphyritic, $23 \%$ barred olivine, $8 \%$ cryptocrystalline, $29 \%$ glass, $1 \%$ CAT, $1 \%$ G-type, $1 \%$ I type, and $0.3 \%$ SM MMs. About $0.05 \%$ were chrondules or contained chondrule fragments and these are included in the RGB category in Fig. 3. Note that Fig. 3 shows more MMs than those studied because we extrapolated the number of MMs in the size fractions 


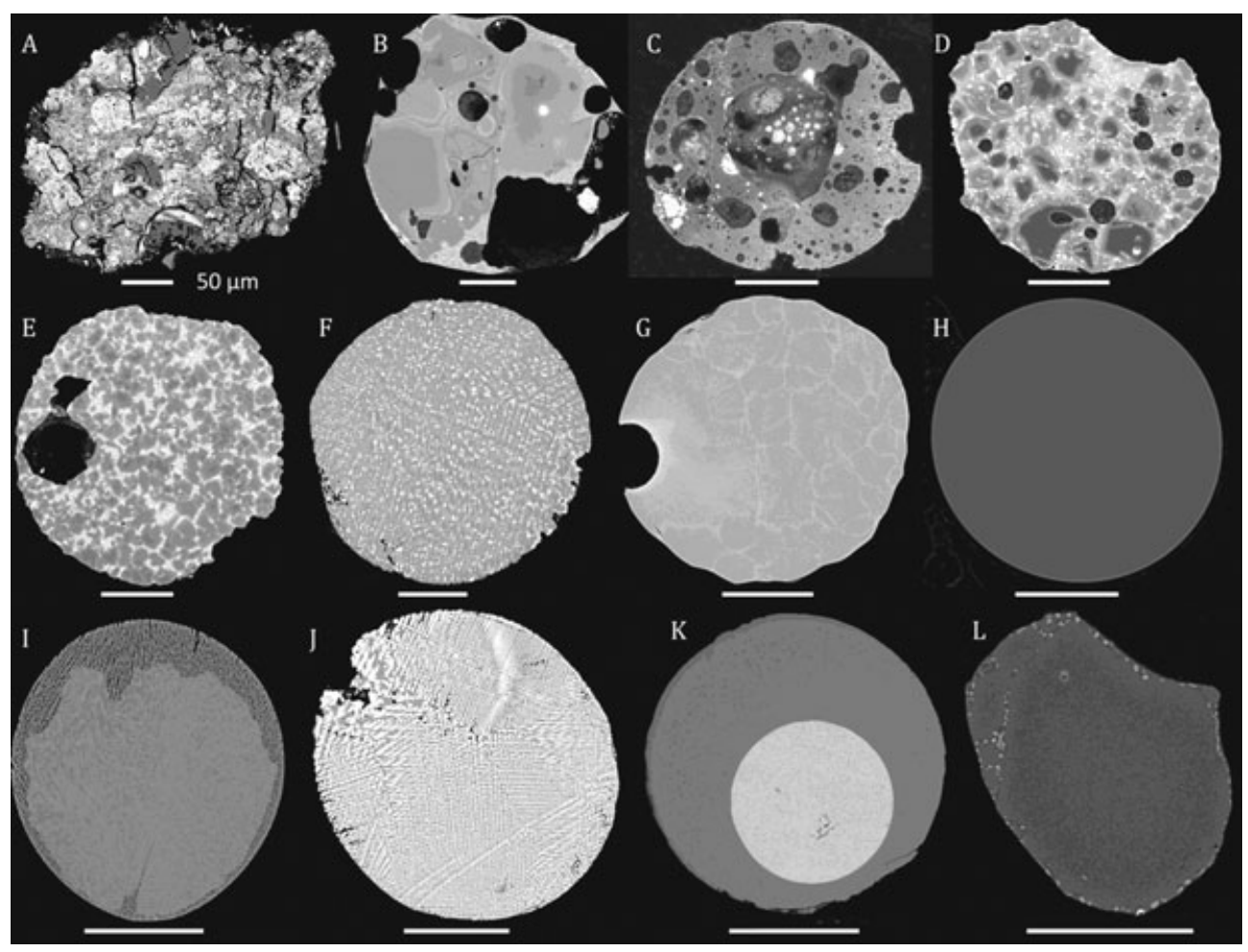

Fig. 1. Micrometeorite (MM) classes: A) Fine-grain unmelted; B) Coarse-grain unmelted; C) Scoriaceous; D) Relict-grain bearing; E) Porphyritic; F) Barred olivine; G) Cryptocrystalline; H) Glass; I) CAT; J) G-type; K) I-type; and L) Single mineral. Scale bars are $50 \mu \mathrm{m}$ and all MMs are from the SPWW.

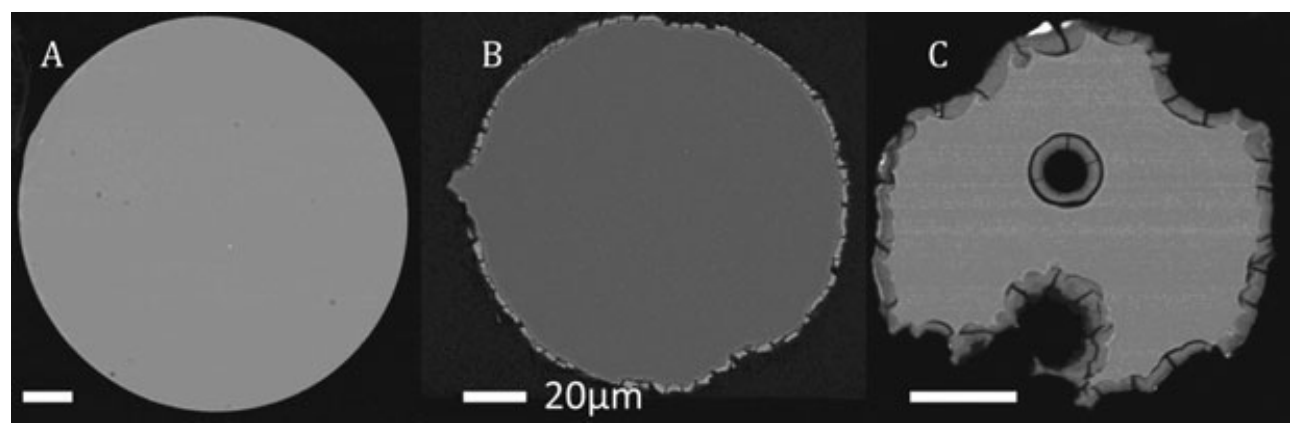

Fig. 2. Examples of un-weathered (A); moderately weathered (B) and highly weathered (C) glass spherules.

where $100 \%$ of the material was not sorted. We assumed that the percentage of MMs in each class in the sorted portion is representative of the unsorted portion.

\section{Micrometeorite Classes in Imaged Particles}

Although optical microscopy is generally sufficient to classify MMs, more detailed observations and analyses require SEM techniques. We imaged 2458 of the 5682 classified MMs using a SEM. The MMs were in 17 mounts and represented different size fractions in the collection. Of those imaged, relict grains were present in about $20 \%$, sulfides were visible in polished section in about $15 \%$ of MMs and chromites in about $5 \%$ of the imaged MMs. The chromites are often cubic indicating that their peripheries have not melted. About $10 \%$ of the MMs were fine-grained unmelted and $2 \%$ were coarsegrained unmelted MMs (Table 1). Of the 183 scoriaceous MMs imaged, $82 \%$ did not contain relict grains in polished section and the relict grains in the other $18 \%$ occupied only a small portion of the particle suggesting that most scoriaceous MMs have fine-grained precursors. We found nine MMs with chondrules, including a MM containing a barred olivine chondrule (Fig. 4A), six spherules that resemble radiating pyroxene chondrules (Fig. 4B), and two MMs containing what appear to be 


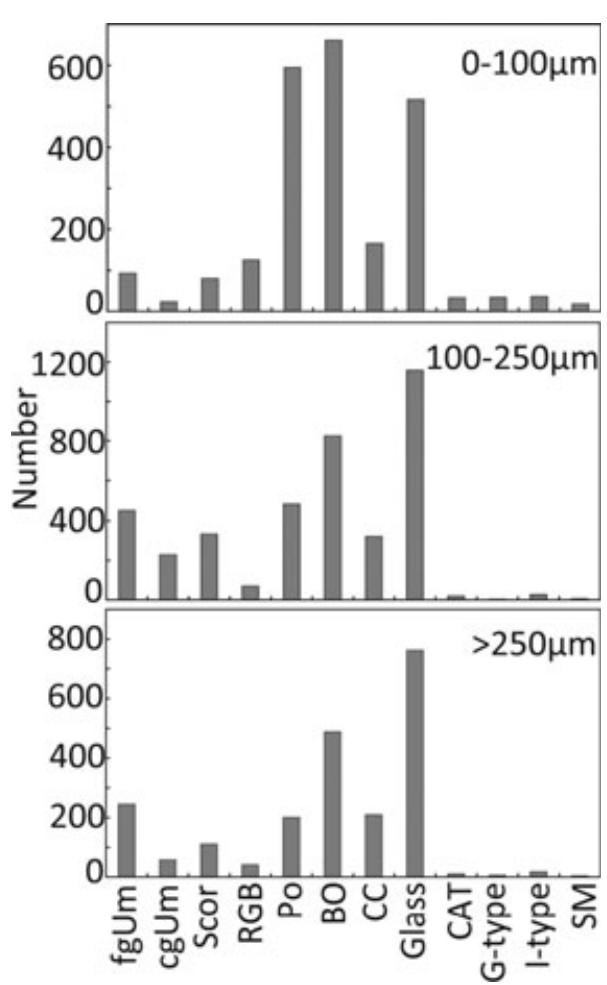

Fig. 3. Number and type of micrometeorites (MMs) found in the 2000 SPWW collection. Types are: fine-grained unmelted (fgUm), coarse-grained unmelted (cgUm), scoriaceous (Scor), relict-grain bearing (RGB), porphyritic (Po), barred olivine (BO), glass, Ca-Al-Ti-rich (CAT), glassy-type (G-type), irontype (I-type), and single mineral (SM).

Table 1. Number of fine-grained and coarse-grained micrometeorite (MM) precursors.

\begin{tabular}{|c|c|c|c|c|c|c|}
\hline 2000 & $\begin{array}{l}\text { No. of } \\
\text { MMs } \\
\text { imaged }\end{array}$ & fgUm & $\begin{array}{l}\text { Scor } \\
\text { no } \\
\text { relicts }\end{array}$ & $\begin{array}{l}\text { Scor } \\
\text { w/relicts }\end{array}$ & $\mathrm{cgUm}$ & RGB \\
\hline Plateau & 1048 & 67 & 71 & 19 & 23 & 1 \\
\hline Pocket & 1410 & 23 & 79 & 14 & 41 & 6 \\
\hline All & 2458 & $11 \%$ & & & $2 \%$ & \\
\hline
\end{tabular}

sections of barred olivine chondrules (Fig. 4C and supplemental materials).

\section{Analyzed Relict Grains}

Relict grains in MM refer to minerals that did not melt during atmospheric entry. We analyzed a subset of the MMs (three mounts) to determine how many contained relict grains that were (1) olivines of a single composition, (2) olivines of two compositions, (3) olivines and pyroxenes, or (4) pyroxenes (Table 2). Results show that fewer relicts are found in MMs with diameter $<250 \mu \mathrm{m}$, and that the relicts in the larger diameter $\mathrm{MMs}$ are generally of one composition, either olivine or pyroxene, but mostly olivines. For the MMs with diameter $<250 \mu \mathrm{m}$, the percentage with relicts increases as does the number of MMs having both pyroxene and olivine relicts. When both olivines and pyroxenes are present, generally the olivine is more $\mathrm{Fe}$ rich than the pyroxene $\left(\mathrm{Fo}_{70-75}, \mathrm{En}_{85}\right)$.

Although most relict grains in $\mathrm{MM}$ are olivines or pyroxenes, feldspars and spinels are also present. Of the 2458 imaged MMs the authors found one anorthite relict, $34 \mathrm{Na}$ feldspar relicts or Na-bearing glasses, and five spinel relicts $\left(\mathrm{MgAlO}_{4}\right)$.

The feldspars are dark in backscatter due to their low atomic number (Figs. 5A and 5B). The MM (SP009, 5-B351) shown in Fig. 5A has an anorthite $\left(\mathrm{CaAl}_{2} \mathrm{Si}_{2} \mathrm{O}_{8}\right)$ and chromite relict in an Fe-rich glass. Analysis of the glass shows $\mathrm{Fe} / \mathrm{Mg}$ to $\mathrm{Fe} / \mathrm{Mn}$ ratios (1.7 and 32.0, respectively) that place it outside the chondritic meteorite field in $\mathrm{Mn}-\mathrm{Mg}-\mathrm{Fe}$ plots and within the field occupied by the HED meteorites and Martian meteorites (Goodrich and Delaney 2000).

We also found albites $\left(\mathrm{NaAlSi}_{3} \mathrm{O}_{8}\right)$ in unmelted to partially melted $\mathrm{MMs}$ that have Fe-bearing pyroxene and olivines and chromite grains and a feldspathic glassy matrix (Fig. 5B, Taylor et al. 2010). Na-rich feldspars are more common than anorthite relicts despite having lower melting temperatures $\left(1100\right.$ versus $1550{ }^{\circ} \mathrm{C}$, Deer et al. 1966). Only one of the feldspar relicts has sharp grain boundaries. The others were partially melted into the surrounding glass at the time of quenching. MMs that have Na-plagioclase relicts are distinctive in appearance, and are often found with $\mathrm{Fe}$ pyroxenes and chromite grains and have vesicles in the glass (Fig. 5B).

The spinel relict grains are also dark in backscatter images, as they contain very little Fe. During atmospheric-entry heating the spinels react with the surrounding glass to form bright, Fe-rich reaction rims (Fig. 6). The temperature at which this reaction occurs must be high as spinel melts at $2135^{\circ} \mathrm{C}$ (Deer et al. 1966). Spinel relicts can be distinguished from forsterite relicts by these reaction rims and the fact that the spinel phenocrysts are often embayed (Taylor et al. 2008). Although spinel has a higher melting point than forsterite, it is much less common in micrometeorites. Spinel is one of a suite of minerals found in CAIs, high temperature condensates found most commonly ( $15 \%$ by volume) in CV meteorites (Sears 1998).

\section{Oxygen Isotope Measurements}

We measured the oxygen isotopic composition of two of the observed spinels to determine if they could be pieces of CAIs. Both spinel relict grains are isotopically 


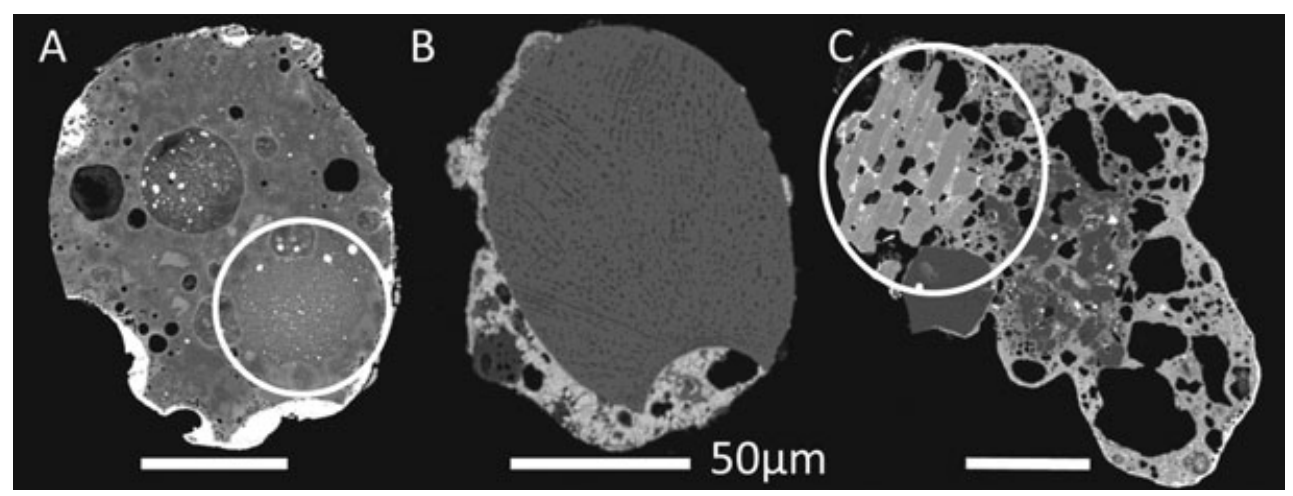

Fig. 4. A) Whole barred olivine (BO) chondrule (within circle); B) whole pyroxene chondrule with attached fine-grained material; C) section of larger $\mathrm{BO}$ chondrule (circled).

Table 2. Percent and types of relict grains in 495 micrometeorites (MMs).

\begin{tabular}{lllllllll}
\hline Diameter $(\mu \mathrm{m})$ & No. of MMs & $\%$ with relicts & $\% 1$ Ol & $\% 2$ Ols & $\%$ ol + pyx & $\%$ pyx & $\%$ spinel & $\%$ plag \\
\hline $250-425$ & 217 & 9 & 6 & 0.5 & 0 & 2 & 0.5 & 0 \\
$106-250$ & 51 & 43 & 22 & 6 & 16 & 0 & 0 & 0 \\
$53-106$ & 227 & 28 & 18 & 2 & 6 & 1 & 0.5 & 1 \\
\hline
\end{tabular}
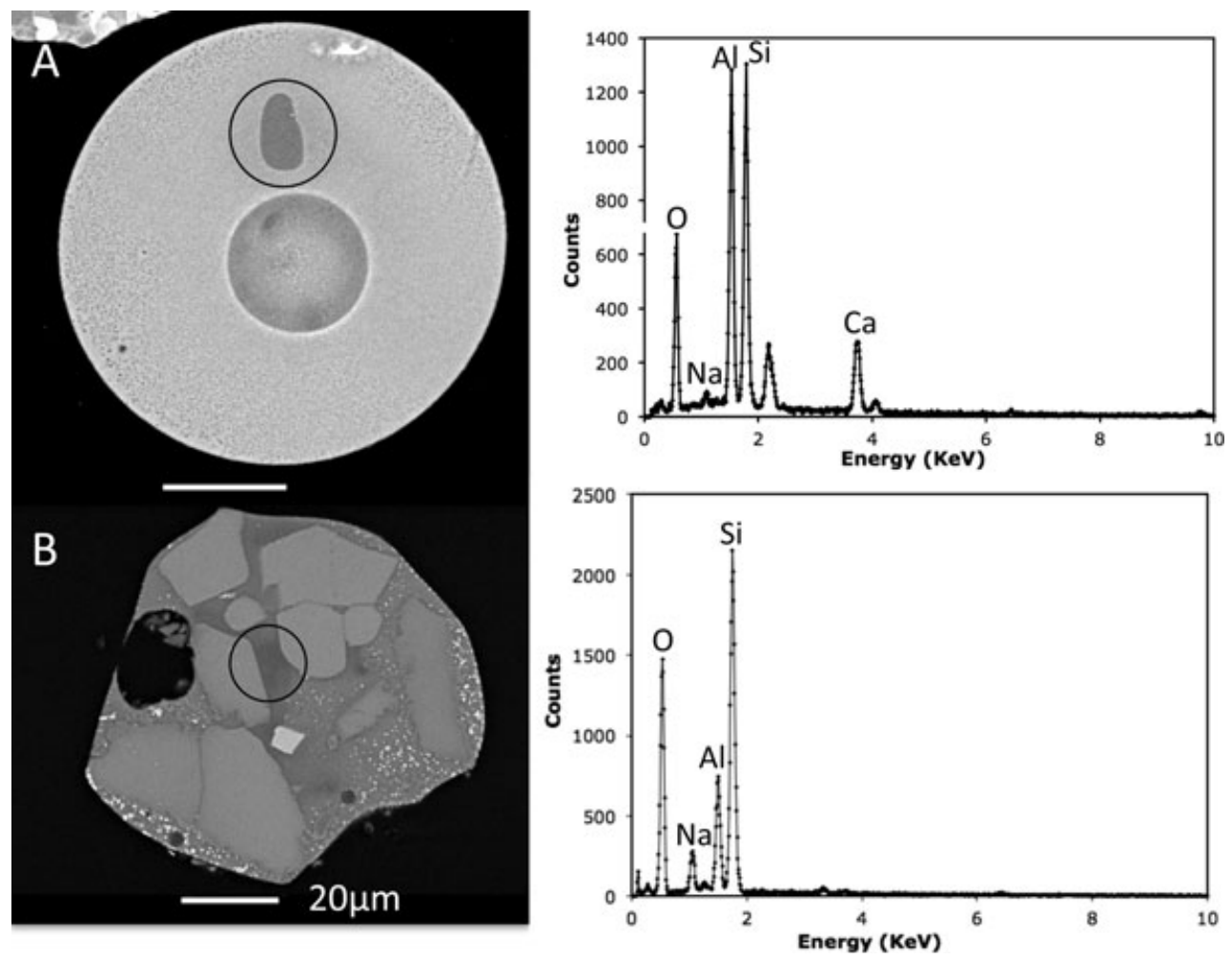

Fig. 5. Images and spectra of: A) anorthite relict grain (solid circle, full size spectrum), and glass (spectrum inset), note chromite in upper right; B) albite relict (within solid circle, full size spectrum) in MM containing olivine (star) and chromite (dashed circle) relict grains. Spectra of olivine $(\mathrm{Mg}, \mathrm{Si}, \mathrm{Fe}$, and $\mathrm{O})$ and chromite $(\mathrm{Cr}, \mathrm{Al}, \mathrm{Fe}$, and $\mathrm{O})$ are shown in inset.

light, $\delta^{18} \mathrm{O}=-27.8$ to $-18.2 \%$ and $\delta^{17} \mathrm{O}=-34.3$ to $-24.3 \%$ o (Fig. 7), similar to spinels from CAIs (Engrand et al. 1999).
We also measured oxygen isotopes in four SM olivine MMs. Many single olivine MMs have light colored or magnetite "zones" around their peripheries 


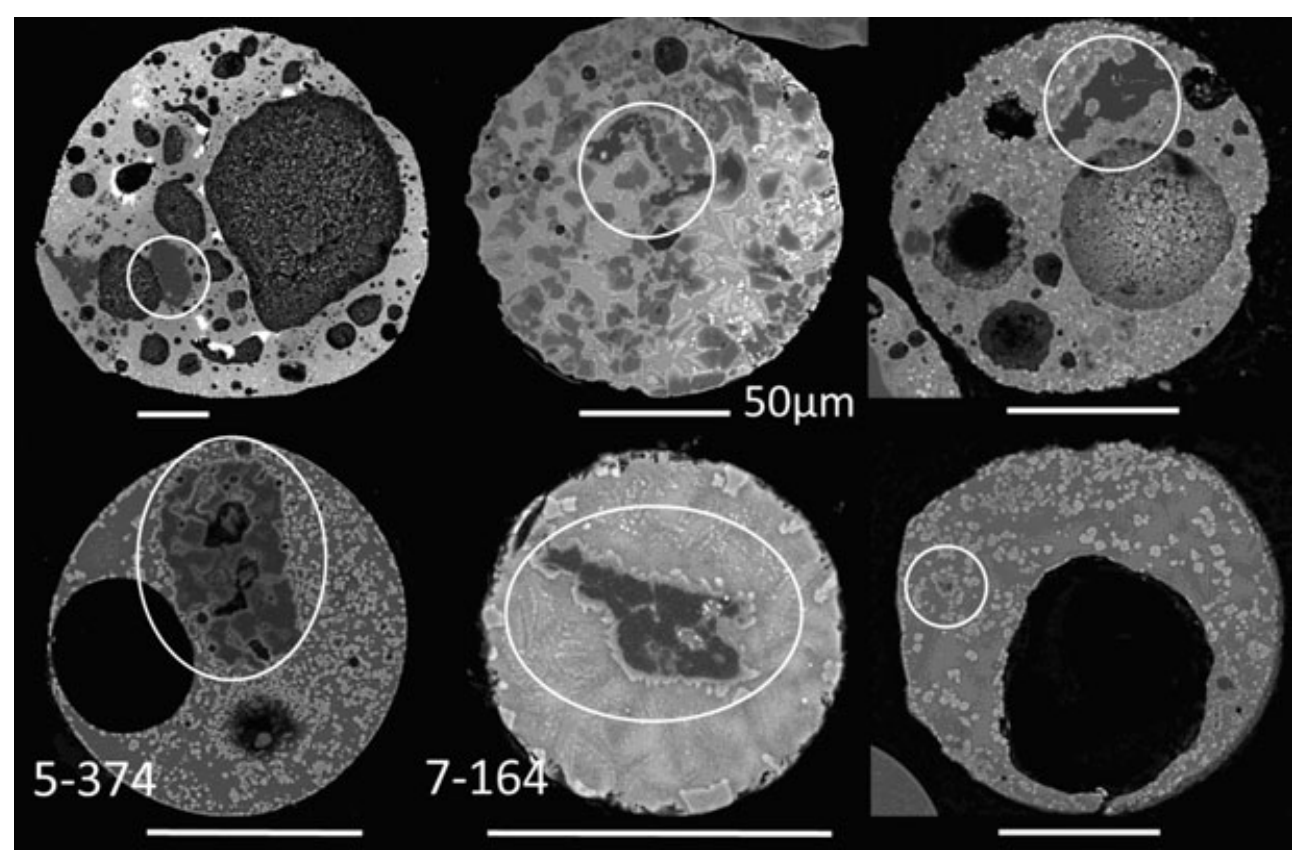

Fig. 6. Relict spinel grains are circled in these micrometeorites. Two of these, 5-374 and 7-164, were analyzed for oxygen isotopes and the results are presented in Fig. 7. All scale bars are $50 \mu \mathrm{m}$.

and we wondered if these zones resulted from oxygen exchange with the Earth's atmosphere during atmospheric entry heating. Figure 8 shows that the size and number of magnetites decreases toward the center of the grain. Analyses from the center of the MMs and adjacent to the magnetite rims are very similar and show only small gradients (Fig. 7). They plot along the CAI line, between $\delta^{18} \mathrm{O}=-8.2-3.3 \%$ and $\delta^{17} \mathrm{O}=-10.6-2.9 \%$, on a three oxygen isotope plot (Fig. 7) in the same region as previously analyzed $\mathrm{MM}$ relict grains (Engrand et al. 1999). The magnetite zone in SP00-7-8 was large enough that we made a measurement within it. This value plots in the same area as the San Carlos olivine standards and is much heavier isotopically than its core (Fig. 7). If the bright rims and magnetite zone defines the area affected by oxygen exchange the rest of the MM probably preserves the pre-entry oxygen isotope values. We also think that atmospheric oxygen exchange is responsible for similar magnetite "zones" seen in relict pyroxenes and olivines within MMs (Figs. 9A-C) and for the bright zones around fine-grained unmelted MM (Fig. 9D), described as cored by Genge et al. (1997).

\section{DISCUSSION}

\section{Heating Effects}

Pristine glasses and abundant sulfides suggest that the SPWW samples have suffered little terrestrial weathering and that changes to their original compositions occurred

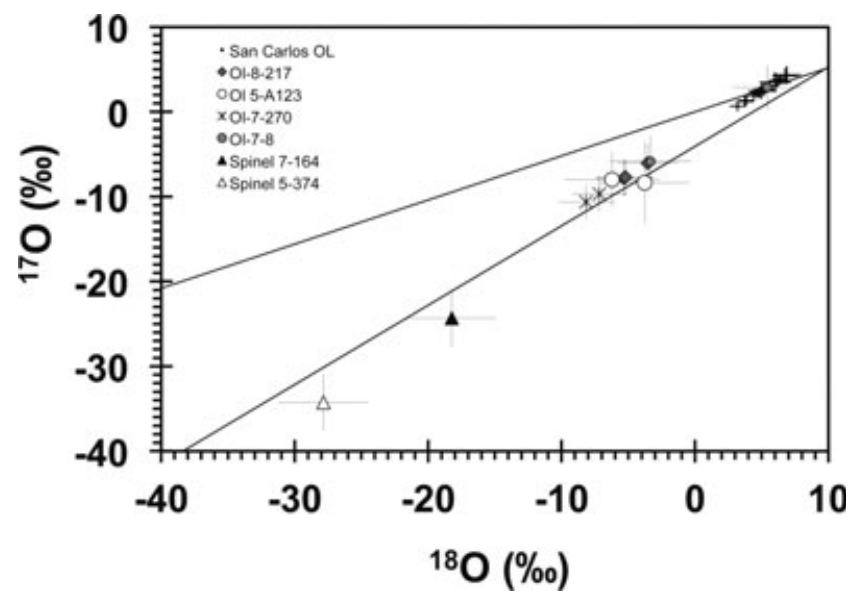

Fig. 7. A three oxygen isotope plot showing data for two spinel grains and four single mineral olivine micrometeorites. The $2 \sigma$ error bars for these data are plotted.

during atmospheric entry heating. The textures and compositions of the resulting micrometeorites will depend on the fraction of matrix to anhydrous mineral phases and the degree of heating. Due to differences in the numbers and sizes of their chondrules, meteorite classes also differ in their matrix to mineral ratios. CIs have few chondrules, whereas by volume CMs have about $20 \%$, CVs about $45 \%$, and OC about $60-80 \%$ (Brearley and Jones 1998).

As MMs are heated and melted, we argue that matrix-dominated MMs produce a different sequence of 


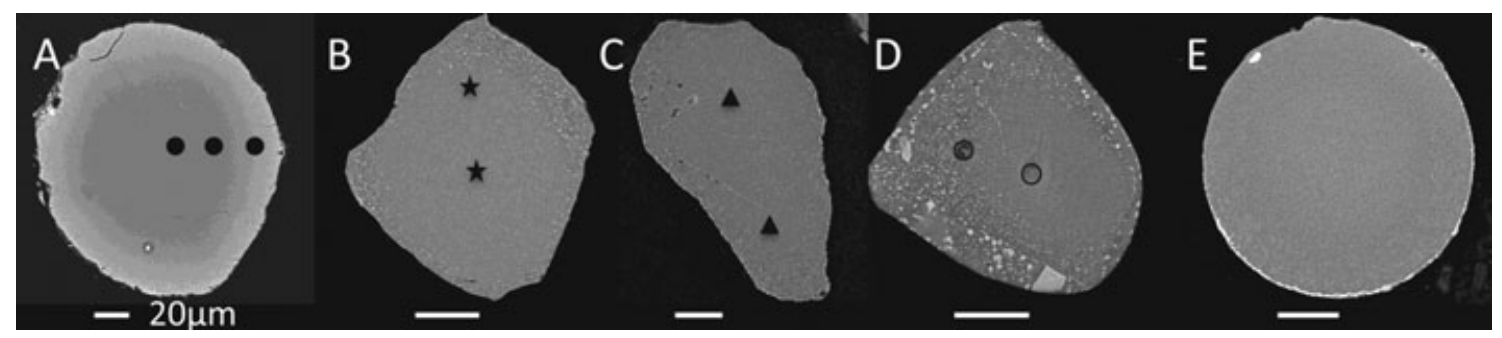

Fig. 8. Single mineral micrometeorites, four olivines and one pyroxene (D). Oxygen isotope analyses, at locations indicated by symbols, for A) 8-217; B) 5-A123; C) 5-A123; and D) 7-8 are plotted in Fig. 7. All scale bars are $20 \mu \mathrm{m}$.

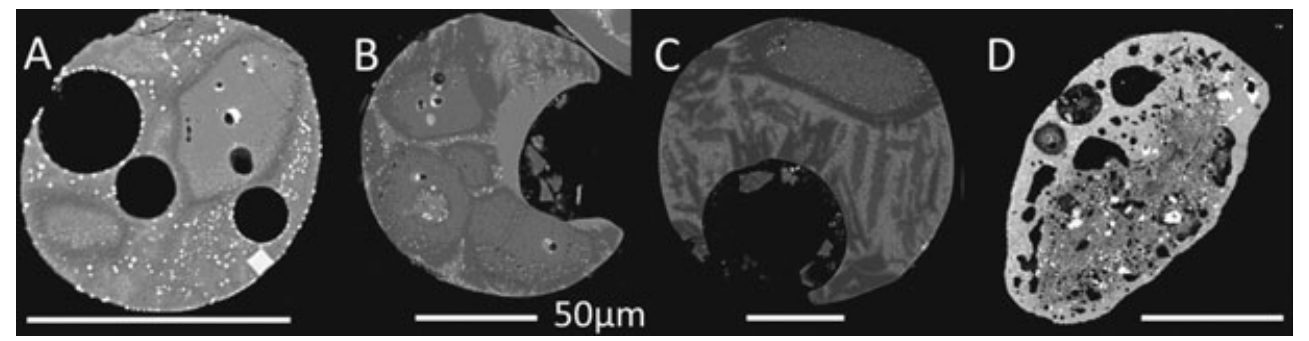

Fig. 9. Relict grains (A, B, C) and cored fine-grained micrometeorite (MM) (D) showing magnetites formed when the MM interacted with terrestrial oxygen during entry heating. All scale bars are $50 \mu \mathrm{m}$.

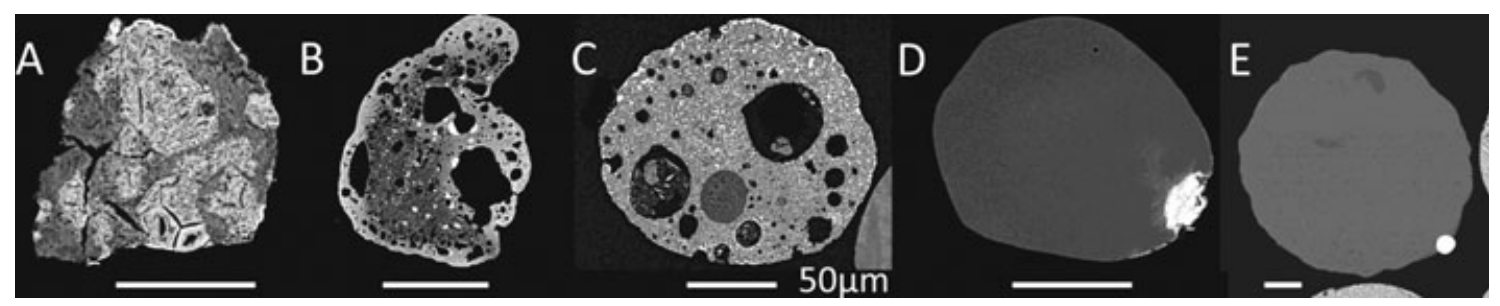

Fig. 10. Changes in micrometeorite textures resulting from heating fine-grained precursor particles. All scale bars are $50 \mu \mathrm{m}$.

textures from those that result when coarse-grained MMs are melted. Below we summarize textural changes we would expect as MMs dominated by matrix or by minerals are heated. We use these melting sequences and equate fine-grained precursor $\mathrm{MMs}$ to $\mathrm{CI}$ and $\mathrm{CM}$ classes and coarse-grained MMs to a variety of meteorite classes including OCs.

\section{Fine-Grained Micrometeorites (Matrix-Dominated Precursors)}

Figure 10 shows a sequence of MM images depicting textures that result as matrix-dominated precursors are heated and melted during atmospheric entry. When first heated, a fine-grained MM develops desiccation features as the sheet silicates loose their bound water (Fig. 10A). Slits appear in the more heated portions of the micrometeorite (brighter areas) (Genge et al. 2008). With further heating, either water from the phyllosilicates or breakdown of sulfides (Taylor et al. 2011) expands the slits to vesicles resulting in a scoriaceous texture
(Fig. 10B). Sulfides disseminated throughout the unmelted MM coalesce to form blebs in the scoriaceous micrometeorites (Taylor et al. 2011). Continued heating lowers the viscosity of the melt allowing any siderophiles to coalesce and the silicates to form rounded or oblate cosmic spherule (Figs. 10C and 10D). Spherules with porphyritic, barred olivine, and glass textures result with progressively increasing temperature. Some glass spherules retain $\mathrm{FeNi}$ beads, the end product of sulfide evaporation (Fig. 10E). CAT spherules result when silicate spherules experience significant evaporation of $\mathrm{Fe}, \mathrm{O}, \mathrm{Si}$, and $\mathrm{Mg}$ (Alexander et al. 2002).

\section{Coarse-Grained Micrometeorites (Anhydrous Mineral Dominated)}

A similar scenario is envisioned for the coarsegrained micrometeoroids. These are generally composed of olivine or pyroxene grains or both with varying amounts of adhering fine-grained phases (Fig. 11A). Anhydrous mineral phases, such as olivine and pyroxene, 


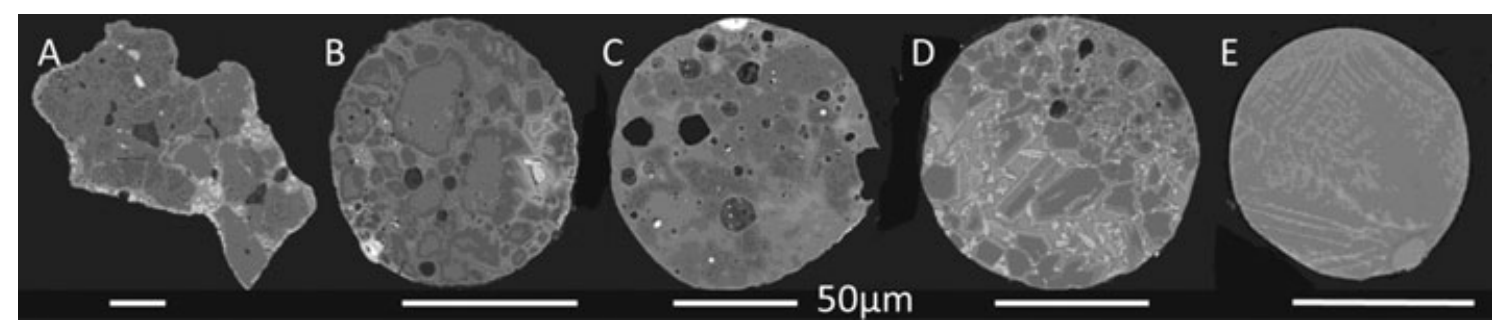

Fig. 11. Changes in micrometeorite textures resulting from heating coarse-grained precursors. All scale bars are $50 \mu \mathrm{m}$.

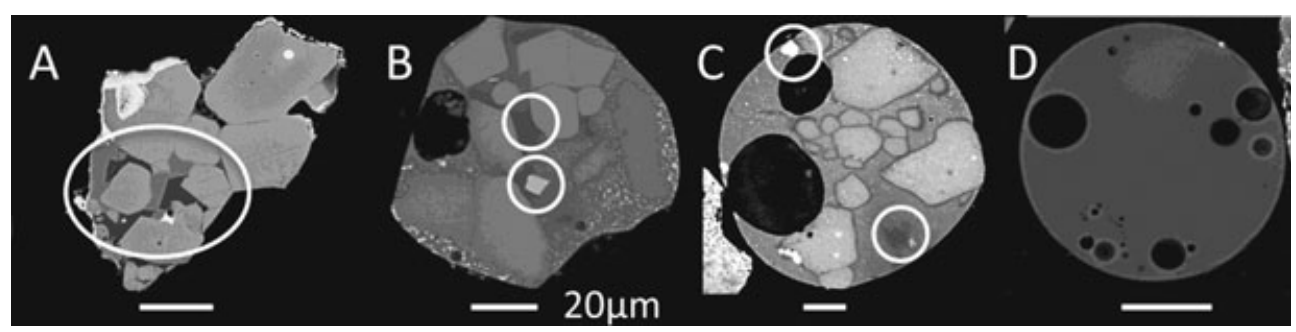

Fig. 12. Images showing: A) unmelted micrometeorite (MM) with albite relicts (circled dark gray phase); B) partially melted and C) almost totally melted MM with circled, plagioclase (dark phase) and chromite (bright phase) relicts; and D) glass spherule formed by a melted feldspar. All scale bars are $20 \mu \mathrm{m}$.

melt at higher temperatures than the fine-grained matrix materials so initial heating melts the fine-grained phases while the pyroxene and olivine remain as relic grains (Fig. 11B). With increased heating, the pyroxene relicts melt leaving forsteritic olivine as the only relict phase (melting points for enstatite $1557^{\circ} \mathrm{C}$, fayalite $1205^{\circ} \mathrm{C}$, forsterite $1890^{\circ} \mathrm{C}$, Deer et al. 1966) (Fig. 11C). Micrometeorites in the size fractions of 53-106 and 106$250 \mu \mathrm{m}$ contain pyroxene relicts, olivine relicts, pyroxene, and olivine relicts and olivine relicts of two compositions, whereas the larger size fractions of $>250 \mu \mathrm{m}$ predominantly have relict grains of forsteritic composition (Table 2) consistent with higher heating for larger particles. Higher or more prolonged heating causes olivine or pyroxene relict grains to break into subunits that are surrounded by melt and give rise to porphyritic (Fig. 11D) and, once completely melted, to barred olivine (Fig. 11E), glass and ultimately CAT spherules. Anhydrous minerals do not produce scoriaceous textures, but if these minerals have a lot of matrix adhering to them, scoriaceous MM containing relict grains can result.

A variation on this theme occurs when coarsegrained MMs containing plagioclase, along with olivine or pyroxene or both, are heated (Figs. 12A-C). These MMs are called type II by Genge (2008). Unmelted MMs have relict grains with sharp crystal boundaries (Fig. 12A). After partial melting, equal-sized olivine or pyroxene relicts remain in a feldspathic glass (Fig. 12B). These $\mathrm{MM}$ are generally quite distinct in appearance as they are not spherical, have vesicles, which are also not spherical, and often contain chromite grains (Figs. 12B and 12C). Complete melting produces glass spherules that can have a range of compositions depending on the relative proportion of the phases in the original micrometeorite. For example, glass spherule pictured in Fig. 12D has a composition suggesting it derived from a Na-feldspar.

\section{Single Mineral Micrometeorites (Anhydrous Minerals)}

Single minerals of olivine, pyroxene, and feldspar also produce micrometeorites. The surfaces of the minerals sometime partially melt or are affected by subsolidus reactions (as modeled by Toppani et al. 2001). Because we see no gradient in isotopic compositions in the interior portions of the grains that are optically similar, we think the surface-altered zone (containing magnetite or brighter than the rest of the MM) formed by reaction with oxygen during atmospheric entry heating. We see similar zones in Fe-containing relict grains within MMs and think they too formed in this manner. Arguments in support of this interpretation are that (1) the number and size of the magnetites decrease away from the surface of the MM; (2) the thickness of the altered zone is quite uniform for a given MM but varies among SM MMs, probably due to differences in the duration and temperature of heating and difference in the composition of the mineral; and (3) iron-free minerals, such as forsterites and feldspars, do not form magnetites. Our data are consistent with the positive correlation found by Suavet et al. (2010) between the amount of magnetite and the $\delta^{18} \mathrm{O}$ value. 


\section{I- and G-Type Micrometeorites}

In the SPWW collection, we find no unmelted MMs that upon melting would give rise to I-type and G-type spherules. The Mn concentration of the glass in the G-type spherules suggests that these spherules may be from enstatite chondrites (Bates 1986). Isotopic and elemental data on I-type spherules suggest they are metal grains released from carbonaceous chondrites (CCs) disaggregated in space (Herzog et al. 1999). I- and G-type spherules are rare in polar collections, they collectively account for about $2 \%$ of the SPWW collection, but are common in the deep-sea samples where they make up between 25 and $50 \%$ and 5 and $25 \%$ of the collection, respectively (Taylor and Brownlee 1991). G-type are generally larger $255 \pm 67 \mu \mathrm{m}(\mathrm{N}=10)$ than I-types $182 \pm 94 \mu \mathrm{m}(\mathrm{N}=54)$ and both can contain FeNi beads.

\section{Implications for Precursor Populations}

\section{Fine-Grained Versus Coarse-Grained Precursors}

If MM textures are linked to their heating history, we can use the melting sequences described above and the textural classes given in Fig. 3 and Table 1 to determine the fraction of micrometeorites derived from predominantly fine-grained (i.e., matrix dominated, CI and $\mathrm{CM}$ ) versus coarse-grained (i.e., anhydrous mineral dominated, OC) precursors. We count fine-grained unmelted and scoriaceous MMs as having fine-grained precursors, and coarse-grained unmelted and relict bearing MMs as having coarse-grained precursors. All other MM textures could result from either fine- or coarse-grained precursors.

For the SPWW sample (Fig. 3: also see this figure for definitions of the class abbreviations) we would predict that $15 \%(9 \%$ fgUm $+6 \%$ scor $)$ were from fine-grained and $7 \%(4 \% \mathrm{cgUm}+3 \% \mathrm{RGB})$ were from coarse-grained precursors. The remaining 78\% (15\% po + $23 \%$ bo $+8 \%$ cc $+29 \%$ glass $+1 \%$ CAT) might form from either type. Fine-grained MM precursors outnumber coarse-grained ones two to one, as was also found in the Cap Prudhomme collection (Genge and Grady 2002). We think this estimate is a lower bound as the percentage determined from the imaged micrometeorites was $85 \%$ fine-grained to $15 \%$ coarse-grained and we think the images used in this study provide a better measure of the fine-grained to coarse-grained ratio.

Except for $\mathrm{CI}$ and $\mathrm{CM}$, the volumes of most chondritic meteorites are dominated by chondrules. Coarse-grained MMs could be derived from chondrules, chondrule fragments, or from minerals that are found with the matrix of all chondrites types. Recognizable chondrules or chondrule fragments, are rare in the SPWW $(<0.5 \%$, this work) and in the Cap Prudhomme

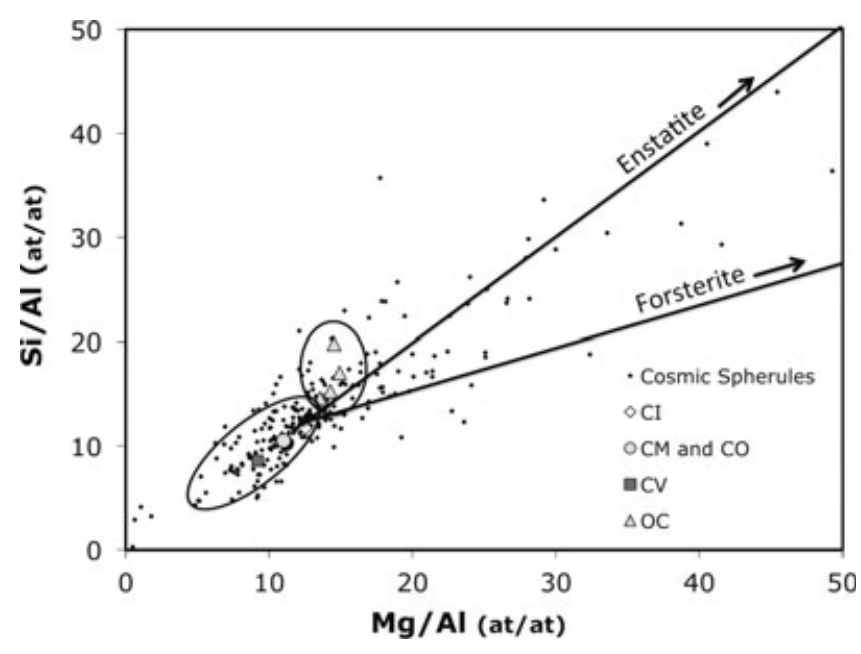

Fig. 13. The $\mathrm{Mg} / \mathrm{Al}$ to $\mathrm{Si} / \mathrm{Al}$ ratios for 263 cosmic spherules and for average matrix values for $\mathrm{CI}, \mathrm{CM}, \mathrm{CO}, \mathrm{CV}$ (large oval), and ordinary chondrite (OC; small oval) meteorites (McSween and Richardson 1977; McSween 1987; and Zolensky et al. 1993). Cosmic spherule analyses are from Taylor et al. (2000, 2005).

$(<1 \%)$ collections (Engrand and Maurette 1998). Furthermore, the chondrules we have found are small $(<100 \mu \mathrm{m}$ in diameter), more similar to chondrules found in CMs $(0.3 \mathrm{~mm})$ than to chondrules in CVs and OCs that are an order-of-magnitude larger (Brearley and Jones 1998). Moreover, $85 \%$ of the relict grains are olivines (Table 2), and many of these are forsterites with compositions similar to forsterites in the CI and $\mathrm{CM}$ meteorites, in other micrometeorites, and in Comet 81P/Wild 2 (Williford et al. 2008). The fine-grained nature of most $\mathrm{MM}$, the lack of chondrules, and the presence of relict phases consistent with $\mathrm{CI}$ and $\mathrm{CM}$ meteorites suggest that the fine-grained precursors make up about $70-85 \%$ of unmelted MMs.

Unmelted MMs, however, only make up a small portion of the MM influx. The fine-grained to coarsegrained fraction in cosmic spherules might be the same as for unmelted MMs but we can estimate the fraction using elemental data. Brownlee et al. (1997) analyzed 500 cosmic spherules and, based on $\mathrm{Mn} / \mathrm{Si}$ versus $\mathrm{Fe} / \mathrm{Si}$ ratios, thought that only about $20 \%$ could derive from coarse-grained precursors. Figure 13 plots $\mathrm{Si} / \mathrm{Al}$ versus $\mathrm{Mg} / \mathrm{Al}$ for previously published microprobe data of SPWW cosmic spherules. Of the 263 spherules analyzed, about $16 \%$ (41) had ratios that plotted in the anhydrous mineral field, along the enstatite and forsterite lines. About $75 \%$ plot in the carbonaceous chondritic field (large oval in Fig. 13) and $10 \%$ in the OC field (small oval). We therefore estimate that $20-30 \%$ of cosmic spherules come from coarse-grained precursors, which would include the OC component. Table 3 lists 
Table 3. Percentage of fine-grained to coarse-grained and of carbonaceous chondrite (CC) to ordinary chondrite (OC) precursors in micrometeorites (MMs).

\begin{tabular}{|c|c|c|c|c|c|c|c|c|}
\hline Method & $\begin{array}{l}\text { No. of } \\
\text { MMs }\end{array}$ & Type & $\begin{array}{l}\text { Diameter } \\
(\mu \mathrm{m})\end{array}$ & $\begin{array}{l}\% \text { Fine- } \\
\text { grained }\end{array}$ & $\begin{array}{l}\text { \% Coarse- } \\
\text { grained }\end{array}$ & $\begin{array}{l}\% \text { CC } \\
\text { (affinity) }\end{array}$ & $\begin{array}{l}\% \text { OC } \\
\text { (affinity) }\end{array}$ & Reference \\
\hline Textures & 2458 & All & $50-1000$ & 85 & 15 & $90(\mathrm{CC})$ & $2-8$ & This work \\
\hline Textures & 77 & $\operatorname{cgUm}$ & $50-400$ & & 100 & 30 & 70 & Genge 2008 \\
\hline Textures & 550 & All & & $\sim 50$ & $\sim 20$ & 70 (CC) & 30 & $\begin{array}{l}\text { Genge and Grady } \\
2002\end{array}$ \\
\hline Textures & 303 & All & $100-400$ & 70 & 17 & $\mathrm{CM}$ & $>1$ & Walter et al. 1995 \\
\hline Textures & 89 & fgUm & & & & $\mathrm{CM}$ & & Genge et al. 1997 \\
\hline $\mathrm{Mg} / \mathrm{Al}, \mathrm{Si} / \mathrm{Al}$ & 169 & Glass & $50-425$ & 74 & 16 & $90(\mathrm{CC})$ & 10 & Taylor et al. 2000 \\
\hline $\mathrm{Mg} / \mathrm{Al}, \mathrm{Si} / \mathrm{Al}$ & 94 & All & $>250$ & 70 & 30 & $\mathrm{CC}$ & 3 & Taylor et al. 2005 \\
\hline $\mathrm{Mg} / \mathrm{Si}, \mathrm{Mn} / \mathrm{Si}$ & 500 & Stony CS & $1-1000$ & 78 & $15(7)$ & $\mathrm{CM}$ & $<25$ & Brownlee et al. 1997 \\
\hline Multiple & 23 & Unmelted & $100-400$ & 70 & 30 & $\mathrm{CM}$ & & Kurat et al. 1994 \\
\hline
\end{tabular}

Table 4. Oxygen isotope measurements of micrometeorites (MMs) showing the measured values relative to the terrestrial fractionation line (TFL) and the inferred meteorite affinity. The down arrow indicates the number of measurements below the TFL and the up arrow the number above.

\begin{tabular}{llllllll}
\hline No. of MMs & Type & Diameter $(\mu \mathrm{m})$ & $\downarrow \Delta \Delta^{17} \mathrm{O}$ TFL & $\uparrow \Delta^{17} \mathrm{O}$ TFL & CCAM & Affinity CC/OC & Reference \\
\hline 33 & CS & $>500$ & 23 & 10 & & 23 CC/8 OC & Suavet et al. 2010 \\
28 & Unmelted & $150-250$ & On TFL & & & CC & Matrajt et al. 2006 \\
14 & CS & $125-195$ & 10 & 4 & & 13 CC $/ 1$ ? & Engrand et al. 2005 \\
8 & CS & $>250$ & 7 on TFL & & 1 & 7 CC/1? & Taylor et al. 2005 \\
48 & CS & $45-300$ & 38 & 3 & 7 & 45 CC/3 OC & Yada et al. 2005 \\
16 & Relict & $50-400$ & & & 16 & CC & Engrand et al. 1999 \\
100 s & CS-bulk & & & & & CM & Clayton et al. 1986 \\
\hline
\end{tabular}

$\mathrm{CC}=$ carbonaceous chondrite; $\mathrm{OC}=$ ordinary chondrite.

published estimates for the fine- to coarse-grained fraction of MM precursors.

\section{Carbonaceous Chondrites Versus OC Component Precursors}

The OC component in MM collections has been estimated using mineral assemblages in unmelted coarsegrained MMs, by the presence of $\mathrm{Na}$ feldpars or feldspathic glasses and by high precision oxygen isotope analyses. Table 3 summarizes published estimates for the $\mathrm{CC}$ to $\mathrm{OC}$ fraction.

Using mineral assemblages, Genge (2008) linked $70 \%$ of coarse-grained unmelted MMs to chondrules from OCs and $30 \%$ to CM-like chondrules. Although the OC fraction may be large in coarse-grained unmelted MMs, these represent only about $3 \%$ of the 2000 collection and so would contribute a $2 \%$ OC component, similar to the fraction estimated from the Prudhomme collection (Walter et al. 1995).

We found 34 Na-bearing plagioclase relicts in the imaged MMs. Because Na-rich feldspars are common in OCs and rare in CI and CM meteorites, if we use them as indicators of OC origin (Taylor et al. 2010) we would again obtain a $2 \%$ OC component. This percentage, however, is likely a minimum because once these MMs melt, the feldspar relicts disappear and their former presence must be determined analytically.

Cosmic spherules resulting from melted feldspars should not plot on the solar $\mathrm{Ca} / \mathrm{Al}$ line as they would have excess Al. Taylor et al. (2000) analyzed 269 glass spherules and, of these, 42 spherules had $\mathrm{Al} / \mathrm{Ca}$ ratios over 2,10 had ratios over 5 , and 4 had ratios over 10 . If all these spherules had contained Na-feldspar we would estimate that $16 \%$ of the glass and cryptocrystalline spherules had derived from OC precursors. Applying the same percentage to the 2000 collection would increase the OC component from 2 to $8 \%$.

Suavet et al. (2010) measured 33 large cosmic spherules (size range $>500 \mu \mathrm{m}$ ) using high precision oxygen isotope analyses. They inferred that $20-50 \%$ of the spherules came from $\mathrm{CO}$ and $\mathrm{CV}$ sources and approximately $30 \%$ from OC sources by correcting for the effect of isotopic fractionation and atmospheric oxygen exchange on the isotopic composition of the cosmic spherules. These results differ from most oxygen isotope data made on smaller MMs, which suggest CC precursors (Table 4). The large OC component found in these $>500 \mu \mathrm{m}$ MMs would result if this size range were capturing the transition from the micrometeorite to the meteorite population (Suavet et al. 2010). 


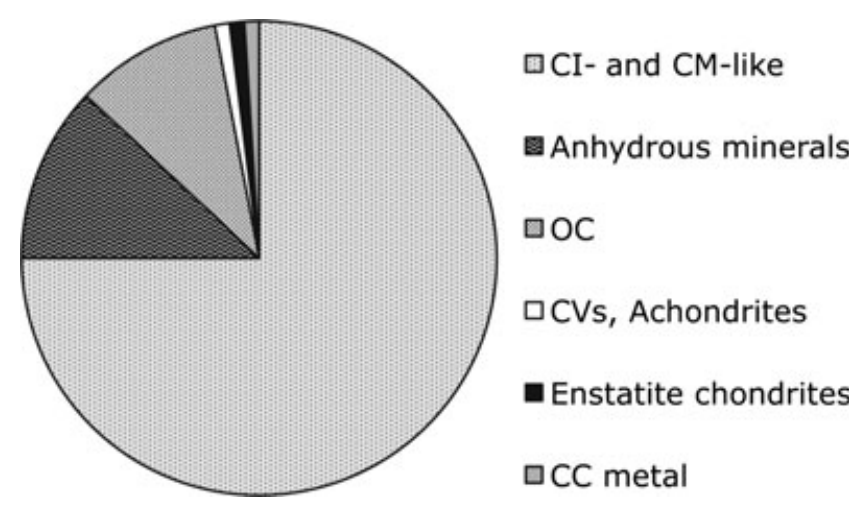

Fig. 14. Best estimate for percent of micrometeorites (MMs) originating from different sources. Fine-grained CI, CM-like material accounts for about $75 \%$ of the MMs. Anhydrous minerals make up $10-15 \%$ and might derive from a variety of chondrites. The ordinary chondrite component is estimated at $\leq 10 \%$ and CVs, achondrites, enstatite chondrites and metal from chondrites are minor contributors $(\sim 1 \%$ each).

Figure 14 summarizes our best estimate for the provenance of the MMs in the 2000 collection. Finegrained CI- and CM-like material produces at least $75 \%$ of the MMs, anhydrous minerals from unspecified sources produce $15 \%$, the OC component is estimated at $10 \%$ or less and other meteorite types produce less than $1 \%$ each. The CVs are estimated based on the number of spinels and the achondrites based on $\mathrm{Fe} / \mathrm{Mn}$ versus $\mathrm{Fe} / \mathrm{Mg}$ ratios. Our estimate suggests that MMs from HED-like objects are rare (HED meteorites are $7 \%$ of meteorite falls); $\mathrm{CVs}$ are rare (CV meteorites are $<1 \%$ of falls); OCs make up 10\% of the MMs (OC meteorites are $\sim 80 \%$ of falls); and that most MMs resemble CI-, CM-like meteorites (CI and CM meteorites are 3\% of falls, Sears 1998).

\section{Asteroidal Versus Cometary Precursors}

The dominance of OCs in meteorite collections $(80 \%$, Sears 1998) and the low number of OC micrometeorites $(<10 \%$ and possibly $3-4 \%)$ presents a conundrum with the following explanations: (1) the OC component in $\mathrm{MM}$ collections has been underestimated (Genge 2008), (2) the CI and CM component in meteorite collections is underestimated because many of these meteorites break up while entering the Earth's atmosphere (Sears 1998), (3) disruption of CC and OC parents in the asteroid belt produce different-sized particle populations-many small $\mathrm{CC}$, few large OCs, or (4) most MMs derive from sources different than those for most meteorites (Nesvorný et al. 2010).

We do not think that the OC component is underestimated in the SPWW collection. If it were, we should see many more coarse-grained unmelted and RGB MMs given the high volume fraction of chondrules in these $\mathrm{OC}$ meteorites.
Sears (1998) suggests that there is a 1000-fold destruction of $\mathrm{CI}$ and $\mathrm{CM}$ meteorites entering the atmosphere. Although this process would produce roughly the correct mass for the MM flux, there is evidence that MMs were small bodies in space (Raisbeck et al. 1986) and breakup of meteorites in the atmosphere occurs at altitudes low enough that the small particles released should vaporize.

Impact disruption experiments of meteorites (Flynn and Durda 2004) indicate that CCs are indeed more friable than OCs and provide a plausible explanation for the compositional difference between MMs and meteorites if the comminution occurred in the asteroid belt. However, many more CI and CM bodies would have to be disaggregated to produce the observed flux.

The possibility that MMs derive preferentially from comets and not asteroids, the likely source of most meteorites, has been discussed for a long time (e.g., Flynn 1989a, 1989b; Engrand and Maurette 1998). The main argument against this was the high entry velocities observed for cometary materials. Particles entering the Earth's atmosphere at $>25 \mathrm{~km} \mathrm{~s}^{-1}$ would likely not survive unless they had shallow entry angles (Love and Brownlee 1991). New dynamical simulations, however, show that the zodiacal cloud can best be produced by material derived from Jupiter family comets (JFCs) (Nesvorný et al. 2010). Nesvorný et al. (2010) contend that JFC particles can be efficiently transported to the inner solar system and that the orbits of $30-300 \mu \mathrm{m}$ particles are circularized, producing velocities low enough $\left(\sim 14 \mathrm{~km} \mathrm{~s}^{-1}\right)$ to produce micrometeorites (velocities comparable to those for asteroidal particles $\sim 12.5 \mathrm{~km} \mathrm{~s}^{-1}$; Nesvorný et al. 2010). They estimate that $85 \%$ of the micrometeoroid flux derives from JFCs.

The only cometary particles from a known source were returned from Wild 2 by the Stardust spacecraft (Brownlee et al. 2006). Many of these tiny particles are fine-grained chondritic materials that contained anhydrous minerals and sulfides. Other grains are SMs, particularly olivines. Chondrules and CAI components have also been identified (see Joswiak et al. 2011). The Wild 2 samples are similar to $\mathrm{MM}$ compositions. Interestingly, the orbital track and velocity of a $\mathrm{CM}$ chondrite, the Maribo meteorite fall, indicate it has a JFC origin (Haack et al. 2010). If JFCs do indeed produce $85 \%$ of the mass influx to Earth as estimated by recent simulations by Nesvorný et al. (2010), and if this dust is CM-like in composition, most MMs may indeed be from JFCs.

\section{CONCLUSIONS}

Micrometeorites can preserve key textural, elemental, and isotopic information about their parent bodies. To interpret the textures, we propose a sequence of textures 
that result as fine-grained, coarse-grained, and SM MMs are heated. Based on fine-grained to coarse-grained ratios of the unmelted micrometeorites we estimate that $70-85 \%$ of the MMs derive from fine-grained materials. Based on elemental analyses of cosmic spherules, we estimate that $75 \%$ of spherules derive from fine-grained materials. The elemental analyses of unmelted MMs and cosmic spherules, the paucity of chondrules, and the composition of relict grains suggest precursors similar to $\mathrm{CI}$ and CM meteorites. OCs, the most common type of meteorite, produce only $2-8 \%$ of the MMs in the 2000 SPWW collection. High-temperature minerals such as spinel and anorthite are found in less than $1 \%$ of the $\mathrm{MMs}$ indicating that $\mathrm{CAI}-$-containing (maybe from $\mathrm{CV}$ chondrites) and achondrite micrometeoroids are rare.

Oxygen isotope measurements of single olivine MMs suggest that only their outer peripheries, marked by the presence of magnetite crystals, exchanged oxygen with the Earth's atmosphere. Iron containing relict grains, within MMs, show similar magnetite zones and this visual marker allows us to select and analyze areas not affected by terrestrial oxygen.

Lastly, the observation that CI- and CM-like materials dominate modern day micrometeorite collections is consistent with $85 \%$ of the mass influx coming JFCs.

Acknowledgments - The authors thank Dave Joswiak and Dr. Hope Ishii for reviewing this article and providing many helpful suggestions. Dr. Gregory Herzog is thanked for the many helpful discussions on this work. We thank NSF (Dr. Julie Palais, program manager) for funding the collection of micrometeorites from the SPWW and NASA (Dr. David Lindstrom, program manager) for funding the analysis of the 2000 collection. The authors also thank Sarah E. Wengert and other Women in Science Project students at Dartmouth College for imaging hundreds of these micrometeorites and Dr. Charles Daghlian for comentoring these students.

\section{Editorial Handling-Dr. Donald Brownlee}

\section{REFERENCES}

Alexander C. M. O’D. 2001. Exploration of quantitative kinetic models for the evaporation of silicate melts in vacuum and in hydrogen. Meteoritics \& Planetary Science 36:255-283.

Alexander C. M. O'D, Taylor S., Delaney J. S., Ma P., and Herzog G. F. 2002. Mass-dependant fractionation of $\mathrm{Mg}$, $\mathrm{Si}$, and $\mathrm{Fe}$ isotopes in five stony micrometeorites. Geochimica et Cosmochimica Acta 66:173-183.

Bates B. A. 1986. The elemental composition of stony extraterrestrial particles from the ocean floor. Ph.D. thesis, University of Washington, Seattle, WA. 199 p.

Beckerling W. and Bischoff A. 1995. Occurence and composition of relict minerals in micrometeorites from
Greenland and Antarctica-implications for their origins. Planetary and Space Science 43:435-449.

Brearley A. J. and Jones R. H. 1998. Chondritic meteorites. In Planetary materials, edited by Papike J. Reviews in Mineralogy vol. 36, Chapt. 3. pp. 1-398. Chantilly, VA: Mineralogical Society of America.

Brownlee D. E, Tsou P., Aléon J., Alexander C. M. O’D., Araki T., Bajt S., Baratta A., Bastien R., Bland P., Bleuet P., Borg J., Bradley J. P., Brearley A., Brenker F., Brennan S., Bridges J. C., Browning N. D., Brucato J. R., Bullock E., Burchett M. J., Busemann H., Butterworth A., Chaussidon M., Cheuvront A., Chi M., Cintala M. J., Clark B. C., Clemett S. J., Cody G., Colangeli L., Cooper G., Cordler P., Daghlian C., Dai Z., D'Hendecourt L., Djouadi Z., Domínguez G., Duxbury T., Dworkin J. P., Ebel D. S., Economou T. E., Fakra S., Fallon S., Fairey S. A. J., Ferrini G., Ferroir T., Fleckenstein H., Floss C., Flynn G., Franchi I. A., Fries M., Gainsforth Z., Gallien J.-P., Genge M., Gilles M. K., Gillet P., Gilmour J., Glavin D. P., Gounelle M., Grady M. M., Graham G. A., Grant P. G., Green S. F., Grossemy F., Grossman L., Grossman J. N., Guan Y., Hagiya K., Harvey R., Heck P., Herzog G. F., Hoppe P., Hörz F., Huth J., Hutcheon I. D., Ignatyev K., Ishii H., Ito M., Jacob D., Jacobsen C., Jacobsen S., Jones S., Joswiak D., Jurewicz A., Kearsley A. T., Keller L. P., Khodja H., Kilcoyne A. L. D., Kissel J., Krot A., Langenhorst F., Lanzirotti A., Le L., Leshin L. A., Leitner J., Lemette L., Leroux H., Liu M.-C., Luening K., Lyon I., MacPherson G., Marcus M. A., Marhas K., Marty B., Matrajt G., McKeegan K., Meibom A., Mennella V., Mesenger K., Messenger S., Mikouchi T., Mostefapio S., Nakamura T., Nakano T., Papanastassiou D. A., Palma R., Palumbo M. E., Pepin R. O., Perkins D., Perronnet M., Pianetta P., Rao W., Rietmeijer F. J. M., Robert F., Rost D., Rotundi A., Ryan R., Sandford S. A., Schwandt C. S., See T. H., Schlutter D., Sheffield-Parker J., Simionovici A., Simon S., Sitnitsky I., Snead C. J., Spencer M. K., Stadermann F. J., Steele A., Stephan T., Stroud R., Susini J., Sutton S. R., Suzuki V., Taheri M., Taylor S., Teslich N., Tomeokoa K., Tomioka N., Toppani A., Trigo-Rodríguez J. M., Troadec D., Tsuchiyama A., Tuzzolino A. J., Tyliszczak T., Uesugi K., Velbel M., Vellenga J., Vicenzi E., Vincze L., Warren J., Weber I., Weisberg M., Westphal A. J., Wi rick S., Woioden D., Wopenka B., Wozniakiewicz P., Wright I., Yabuta H., Yano H., Young E. D., Zare R. N., Zega T., Ziegler K., Zimmerman L., Zinner E., and Zolensky M. 2006. Comet 81P/Wild 2 under a microscope. Science 314:1711-1716.

Brownlee D. E., Bates B., and Schram L. 1997. The elemental composition of stony cosmic spherules. Meteoritics \& Planetary Science 32:157-175.

Clayton R. N., Mayeda T., and Brownlee D. E. 1986. Oxygen isotopes in deep-sea spherules. Earth and Planetary Science Letters 79:235-240.

Cordier C., Folco L., and Taylor S. 2011. Vestoid cosmic spherules from the South Pole Water Well and Transantarctic Mountains (Antarctica): A major and trace element study. Geochimica et Cosmochimica Acta 75:11991215.

Deer W. A., Howie R. A., and Zussman J. 1966. An introduction to the rock forming minerals. London: Longman Group Limited. 528 p.

Engrand C. and Maurette M. 1998. Carbonaceous micrometeorites from Anarctica. Meteoritics \& Planetary Science 33:565-580. 
Engrand C., McKeegan K. D., and Leshin L. A. 1999. Oxygen isotopic composition of individual minerals in Antarctic micrometeorites: Further links to carbonaceous chondrites. Geochimica et Cosmochimica Acta 63:2623-2636.

Engrand C., McKeegan K. D., Leshin L. A., Herzog G. F., Schnabel C., Nyquist L. E., and Brownlee D. E. 2005. Isotopic compositions of oxygen, iron, chromium, and nickel in cosmic spherules: Toward a better comprehension of atmospheric entry heating effects. Geochimica et Cosmochimica Acta 69:5365-5385.

Flynn G. J. 1989a. Atmospheric entry heating: A criterion to distinguish between asteroidal and cometary sources of interplanetary dust. Icarus 77:287-310.

Flynn G. J. 1989b. The near-Earth enhancement of asteroidal over cometary dust. Proceedings, 20th Lunar and Planetary Science Conference. pp. 363-371.

Flynn G. J. and Durda D. 2004. Chemical and mineralogical size segregation in impact disruption of inhomogeneous, anhydrous meteorites. Planetary and Space Science 52:1129-1140.

Genge M. J. 2008. Koronis asteroid dust within Antarctic ice. Geology 36:687-690.

Genge M. J. and Grady M. M. 2002. The distribution of asteroids: Evidence from Antarctic micrometeorites (abstract \#1010). 33rd Lunar and Planetary Science Conference. CD-ROM.

Genge M. J., Grady M. M., and Hutchison R. 1997. The textures and compositions of fine-grained Antarctic micrometeorites: Implications for comparisons with meteorites. Geochimica et Cosmochimica Acta 61:51495162.

Genge M. J., Engrand C., Gounelle M., and Taylor S. 2008. The classification of micrometeorites. Meteoritics \& Planetary Science 43:497-515.

Goodrich C. A. and Delaney J. S. 2000. Fe/Mg-Fe/Mn relations of meteorites and primary heterogeneity of primitive achondrite parent bodies. Geochimica et Cosmochimica Acta 64:149-160.

Greshake A., Klock W., Arndt P., Maetz M., Flynn G. J, Bajt S., and Bischoff A. 1998. Heating experiments simulating atmospheric entry heating of micrometeorites: Clues to their parent body sources. Meteoritics \& Planetary Science 33:267-290.

Haack H., Michelsen R., Stober G., Keuer D., and Singer W. 2010. The Maribo CM2 Fall: Radar based orbit determination of an unusually fast fireball (abstract \#5085). 73rd Annual Meeting of the Meteoritical Society. Meteoritics \& Planetary Science 45.

Herzog G. F., Xue S., Hall G. S., Nyquist L. E., Shih C.-Y., Wiesmann H., and Brownlee D. E. 1999. Isotopic and elemental composition of iron, nickel, and chromium in type I deep-sea spherules: Implications for origin and composition of the parent micrometeoroids. Geochimica et Cosmochimica Acta 63:1443-1457.

Imae N., Taylor S., and Iwata N. 2010. Relict grains in seven unmelted micrometeorites and their common link to chondrules in carbonaceous chondrites. 33rd Symposium on Antarctic Meteorites. National Institute of Polar Research, Japan. pp. 28-29.

Joswiak D. J., Brownlee D. E., Matrajt G, Westphal A. J., and Snead C. J. 2011. Comprehensive examination of large mineral and rock fragments in Stardust tracks: Mineralogy, analogous ET materials and source regions. Meteoritics \& Planetary Science. This issue.
Kuivinen K. C., Koci B. R., Holdsworth G. W., and Gow A. J. 1982. South Pole ice core drilling, 1981-1982. Antarctic Journal of the United States 17:89-91.

Kurat G., Koeberl C., Presper T., Brandstätter F., and Maurette M. 1994. Petrology and geochemistry of Antarctic micrometeorites. Geochimica et Cosmochimica Acta 58:3879-3904.

Leshin L.A., Rubin A. E., and McKeegan K. D. 1997. The oxygen isotopic composition of olivine and pyroxene from CI chondrites. Geochimica et Cosmochimica Acta 61:835845.

Love S. G. and Brownlee D. E. 1991. Heating and thermal transformation of micrometeoroids entering the Earth's atmosphere. Icarus 89:26-43.

Love S. G. and Brownlee D. E. 1993. A direct measurement of the terrestrial mass accretion rate of cosmic dust. Science 262:550-553.

Matrajt G., Guan Y., Leshin L., Taylor S., Genge M., Joswiak D., and Brownlee D. E. 2006. Oxygen isotope measurements of individual unmelted Antarctic micrometeorites. Geochimica et Cosmochimica Acta 70:4007-4018.

McSween H. Y. 1987. Aqueous alteration in carbonaceous chondrites: Mass balance constraints on matrix mineralogy. Geochimica et Cosmochimica Acta 51:2469-2477.

McSween H. Y. and Richardson S. M. 1977. The composition of carbonaceous chondrite matrix. Geochimica et Cosmochimica Acta 41:1145-1161.

Nesvorný D., Jenniskens P., Levison H. F., Bottke W. F., Vokrouhlicky D., and Gounelle M. 2010. Cometary origin of the zodiacal cloud and carbonaceous micrometeorites. Implications for hot debris disks. The Astrophysical Journal 713:816-836.

Raisbeck G. M., Yiou F., Bourles D., and Maurette M. 1986. ${ }^{10} \mathrm{Be}$ and ${ }^{26} \mathrm{Al}$ in Greenland Cosmic spherules: Evidence for irradiation in space as small objects and probably cometary origin. Meteoritics 21:487-488.

Sears D. W. G. 1998. The case for rarity of chondrules and calcium-aluminum-rich inclusions in the early solar system and some implications for astrophysical models. Astrophysical Journal 498:773-778.

Steele I. M. 1990. Minor elements in forsterites of Orgueil (C1), Alais $(\mathrm{C} 1)$ and two interplanetary dust particles compared to C2-C3-UOC forsterites. Meteoritics 25:301-307.

Steele I. M. 1992. Olivine in Antarctic micrometeorites: Comparison with other extraterrestrial olivine. Geochimica et Cosmochimica Acta 56:2923-2929.

Steele I.M, Smith J. V., and Brownlee D. E. 1985. Minorelement signature of relic olivine grains in deep-sea particles - A match with forsterites from $\mathrm{C} 2$ meteorites. Nature 313:297-299.

Suavet C., Alexandre A., Franchi I. A., Gattacceca J., Sonzogni C., Greenwood R. C., Folco L., and Rochette P. 2010. Identification of the parent bodies of micrometeorites with high precision oxygen isotope ratios. Earth and Planetary Science Letters 293:313-320.

Taylor S. and Brownlee D. E. 1991. Cosmic spherules in the geologic record. Meteoritics 26:203-211.

Taylor S. and Lever J. H. 2001. Seeking unbiased collections of modern and ancient micrometeorites. In Accretion of extraterrestrial matter throughout Earth's history, edited by Peucker-Erhenbrink B. and Schmitz B. New York: Kluwer Academic/Plenum Publishers. pp. 205-219.

Taylor S., Lever J. H., Harvey R. P., and Govoni J. 1997. Collecting micrometeorites from the South Pole water well, 
CRREL Report 97-1, Cold Regions Research and Engineering Laboratory, Hanover, NH.

Taylor S, Lever J. H., and Harvey R. P. 1998. Accretion rate of cosmic spherules measured at the South Pole. Nature 392:899-903.

Taylor S, Lever J. H., and Harvey R. P. 2000. Numbers, types and compositions of an unbiased collection of cosmic spherules. Meteoritics \& Planetary Science 35:651666.

Taylor S., Alexander C. M. O’D., Delaney J., Ma P., Herzog G. F., and Engrand C. 2005. Isotopic fractionation of iron, potassium, and oxygen in stony cosmic spherules: Implications for heating histories and sources. Geochimica et Cosmochimica Acta 69:2647-2662.

Taylor S., Herzog G. F., and Delaney J. S. 2007. Crumbs from the crust of Vesta: Achondritic cosmic spherules from the South Pole water well. Meteoritics \& Planetary Science 42:223-233.

Taylor S, Alexander C. M. O’D., and Wengert S. 2008. Rare micrometeorites from the South Pole, Antarctica (abstract \#1628). 39th Lunar and Planetary Science Conference. CD-ROM.

Taylor S., Lindsay F. N., and Delaney J. S. 2010. Albitic plagioclase in micrometeorites from the South Pole water well, Antarctica (abstract \#5051). 74th Annual Meeting of the Meteoritical Society. Meteoritics \& Planetary Science 45.

Taylor S., Jones K. W., Herzog G. F., and Hornig C. E. 2011. Tomography: A window on the role of sulfur in the structure of micrometeorites. To appear in Meteoritics \& Planetary Science 46:1498-1509.
Toppani A., Libourel G., Engrand C., and Maurette M. 2001. Experimental simulation of atmospheric entry of micrometeorites. Meteoritics \& Planetary Science 36:13771396.

Trigo-Rodríguez J. M., Llorca J., Borovička J., and Fabregat J. 2003. Chemical abundances determined from meteor spectra: I. Ratios of the main chemical elements. Meteoritics \& Planetary Science 38:1283-1294.

Walter J., Kurat G., Brandstatter F., Koeberl C., and Maurette M. 1995. The abundance of ordinary chondrite debris among Antarctic micrometeorites (abstract). Meteoritics 30:592-593.

Williford K., Taylor S., Matrajt G., Brownlee D. E., Joswiak D., Wengert S., and Kuehner S. 2008. Comparing olivine compositions from micrometeorites with those from other solar system materials (abstract \#2269). 39th Lunar and Planetary Science Conference. CD-ROM.

Yada T., Nakamura T., Noguchi T., Matsumoto N., Kusakabe M., Hiyagon H., Ushikubo T., Sugiura N., Kojima H., and Takaoka N. 2005. Oxygen isotopic and chemical compositions of cosmic spherules collected from the Antarctic ice sheet: Implications for their precursor. Geochimica et Cosmochimica Acta 69:5789-5804.

Zolensky M., Barrett R., and Browning L. 1993. Mineralogy and composition of matrix and chondrule rims in carbonaceous chondrites. Geochimica et Cosmochimica Acta 57:3123-3148.

Zolensky M., Bland P., Brown P., and Halliday I. 2006. Flux of extraterrestrial materials. In Meteorites and the early solar system II, edited by Lauretta D. S. and McSween H. Y. Tucson, AZ: University of Arizona Press. pp. 869-888. 